\title{
Complexity management in project organisations
}

\author{
Hansen, Zaza Nadja Lee; Haug, Anders; Afandi, Said; Hvam, Lars
}

Published in:

Production Engineering

Link to article, DOI:

10.1007/s11740-021-01033-7

Publication date:

2021

Document Version

Peer reviewed version

Link back to DTU Orbit

Citation (APA):

Hansen, Z. N. L., Haug, A., Afandi, S., \& Hvam, L. (2021). Complexity management in project organisations. Production Engineering, 15, 361-370. https://doi.org/10.1007/s11740-021-01033-7

\section{General rights}

Copyright and moral rights for the publications made accessible in the public portal are retained by the authors and/or other copyright owners and it is a condition of accessing publications that users recognise and abide by the legal requirements associated with these rights.

- Users may download and print one copy of any publication from the public portal for the purpose of private study or research.

- You may not further distribute the material or use it for any profit-making activity or commercial gain

- You may freely distribute the URL identifying the publication in the public portal

If you believe that this document breaches copyright please contact us providing details, and we will remove access to the work immediately and investigate your claim 


\title{
Complexity Management in Project Organisations
}

\begin{abstract}
Managing costs is vital to developing profitable organisations. Whilst the literature stresses the importance of managing complexity in production companies, little attention has been given to project-based organisations. Thus, this paper investigates the research gap that exists for project organisations within the field of complexity management. The aim is to create a conceptual understanding of where complexity may be found in project organisations, thereby, paving the way for understanding the impact of complexity on operational performance. In order to accomplish this, a case study was conducted to understand complexity drivers and their effects in project organisations. The study has two main findings. First, three main complexity drivers in project organisations are identified: (1) project risks, (2) personal preferences and capabilities and (3) project management. Second, based on the case study, seven guidelines for project organisations engaging in complexity management projects are developed. The results provide new knowledge of complexity management in project organisations, thereby, enriching current complexity management frameworks. Given the novelty of the topic, several points of interest are identified as possible follow-up research areas, which include an investigation of other project organisations to generalise the research findings and a study of the detailed cost breakdown of project execution to identify areas where the least profitable projects consume incremental resources.
\end{abstract}

Keywords: Complexity management, project organisations, operational performance, case study research

\section{INTRODUCTION}

Complexity increases in modern organisations with more complicated products, supply chains and sales channels (Cooper and Kaplan, 1988; Rauch et al., 2018; Schuh et al., 2008). This complexity assumes different forms in manufacturing systems, such as product complexity, process complexity and organisational complexity (Wilson and Perumal, 2010). Complexity occurs in positive and negative forms, as captured by the distinction between value-adding and non-value-adding complexity (Haug et al., 2013; Scheiter et al., 2007). Whilst properly managed complexity is a value-adding competitive advantage to a company, excessive or unmonitored complexity results in profit losses (ElMaraghy et al., 2013; Scheiter et al., 2007; Wilson and Perumal, 2010). In this context, it should be noted that complexity management goes beyond product portfolio management and standardisation of production processes, but it is encountered in organisations across all sectors (Afandi and Hansen, 2016). Understanding complexity is important, as it impacts personal and organisational productivity, the work environment, customer experience and profit (Ashkenas, 2007).

Because of the rising knowledge economy, a growing number of organisations operate in a project-based manner (Svejvig et al., 2016). A company's project structure can be understood in several ways, and it can include entirely project-based organisations or companies that have a project subsidiary or project organisation that supports them. Project organisations are a combination of production companies and project companies, and they are subject to challenges related to both.

Most research that identifies or reduces complexity has focused on product variety, portfolio management and the identification of production-related complexities for production or service companies (Blecker and Kersten, 2006; Wilson and Perumal, 2009; Collinson and Jay, 2012; Hansen et al., 2012). However, based on our literature review, there does not seem to be complexity management specifically targeted at project organisations. This paper addresses this research gap through the following research question:

\section{What are the main complexity drivers in project organisations, and how can these be addressed?}

The remainder of the paper is structured as follows. Section 2 presents the literature review, after which Section 3 explains the methodology. Next, Section 4 presents the case study findings and Section 5 provides a discussion of the findings, including contributions, limitations and future research.

\section{LITERATURE REVIEW}

\subsection{Review process}

The literature review uses a funnel approach. Specifically, beginning with a broad explorative focus to understand the context surrounding the topic, the literature is then narrowed down to highlight the most relevant research within the topic (Saunders et al., 2009). The literature review is based on research papers, 
white papers, academic books and other sources and focuses on the topic of complexity management, particularly complexities that relate to project-based production. Table 1 summarises the literature search process.

Table 1 Summary of the literature search process

\begin{tabular}{ll}
\hline Concept & Complexity management \\
\hline Search terms & $\begin{array}{l}\text { 'complexity', 'complexity management', 'complexity reduction', 'project complexity', 'process } \\
\text { complexity', 'organisational complexity', 'cost cutting', 'project production', 'production complexity', } \\
\text { 'project production complexity', 'activity-based costing', 'ABC analysis' } \\
\text { Sources }\end{array}$ \\
$\begin{array}{l}\text { Google Scholar, DTU Findit, LibSearch, academia.edu, web search } \\
\text { Preliminary literature }\end{array}$ & $\begin{array}{l}\text { Articles (conferences, journal articles and whitepapers), books, web pages } \\
\text { Focused literature }\end{array}$ \\
Final literature & 86 sources \\
\hline
\end{tabular}

\subsection{Identified literature}

Complexity management involves all processes within an organisation, including its offerings, structure, managerial systems and financial procedures, as well as external environmental influences, such as partners, competitors and government regulations (Kohr et al., 2017). Complexity has been a theme for many studies of production firms including production systems (Schuh et al., 2011), logistics processes (Sowade et al., 2013), value chains (Rauch et al., 2018), product modularity (Hvam et al., 2017), location-inventory decisions (Kuhnle and Lanza, 2019), production outsourcing (Wildemann, 2005), and job shops (Altenmüller et al., 2020). On the other hand, the identified literature did not include organisations directly comparable to project organisations.

The identified literature on complexity management may, from an overall perspective, be organised under the dimensions:

- Organisational complexity concerns the way organisations are configured. The largest threats are "silo mentality" and the processes which determine how people work with governance structures. The focus must penetrate the sub-systems of the organisation, otherwise known as its resources.

- Individual complexity focuses on the perceptions of individuals - things, processes and distractions that make it difficult for individuals to stay productive - which is a topic linked to systems thinking and managerial complexity.

- Managerial complexity covers human interactions and how governance models hinder individual efficiency.

- Process complexity arises internally and externally. Inefficient processes lead to revision, workarounds and duplications, resulting in extended lead times, poor understandability, errors and inconsistent performance.

The drivers of project complexity include technology, methodology, deliverables, budgeting and other unforeseen factors. The literature points to two main sources of project complexity: number and intricacy of interrelated parts. These elements are not easily quantifiable but subject to interpretation.

Based on Sheffield et al.'s (2012) research, Figure 1 (to the left) describes four types of projects based on differing system structures. The matrixes illustrate research conclusions that the project type is based on both the number of interactions and the number of components. Figure 1 (to the right) defines the project management method best suited for each project type.
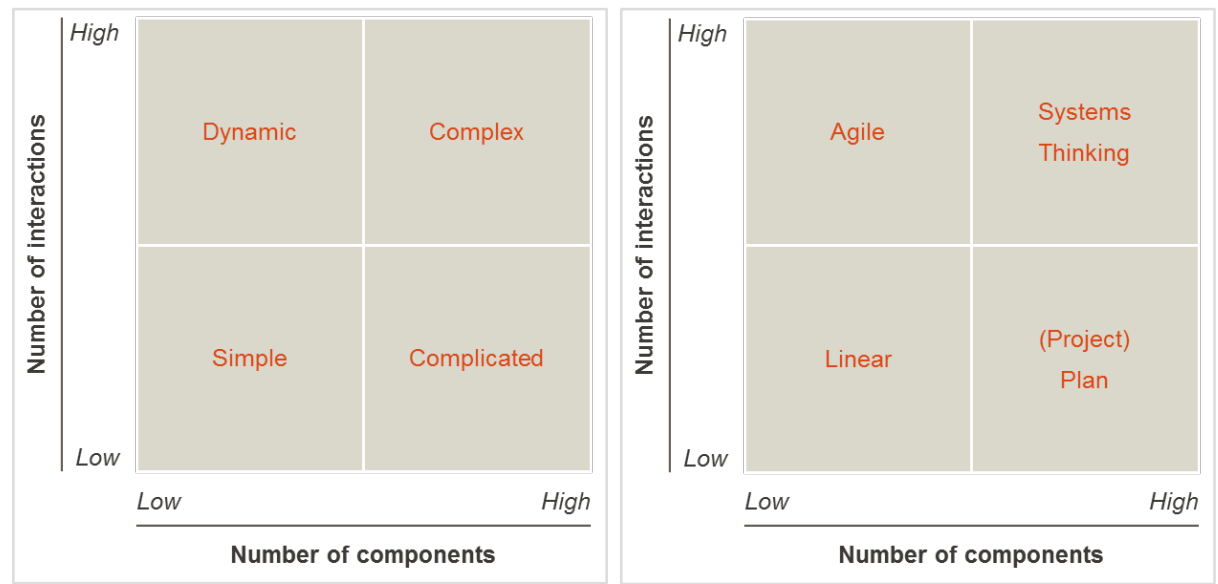

Fig. 1 Types of systems and projects and types of project management methods (Sheffield et al. 2012) 
Shenhar and Dvir (2004) argue that the main source of complexity is technological uncertainty, which eventually distresses the development phases, design cycles and testing. Technology complexity also plays a part in project management, where it affects operations, material characteristics and knowledge characteristics (Baccarini, 1996). Thus, project managers must be able to handle technology complexity and steer project teams to completion while facing uncertainty related to internal and external factors (Camci and Kotnour, 2006). In this context, Forrester's (1989) system dynamics advocates a holistic view of systems and organisations (in contrast to independent units), thereby, enabling an understanding of interrelatedness and cause and effect within and across systems.

Understandability and transparency are essential to quantifying complexity costs. Therefore, activitybased costing is included in the literature review. Activity-based costing enables the allocation of costs to distinctive activities and the calculation of the true cost of serving a customer. Combining activity-based costing with $\mathrm{ABC} /$ Pareto analysis and the Pareto principle creates the methodology used for portfolio analysis and management (Heap, 2021; Koch, 1999; Teunter et al., 2010). However, there are also more overall methods for addressing complexity costs, which include activity-based costing, ABC analysis and other approaches. Table 2 summarises the advantages and disadvantages of the strategies identified in the literature.

Table 2 Selected key strategies to target complexity and the related costs

\begin{tabular}{|c|c|c|c|}
\hline Strategy & Source & Pros & Cons \\
\hline Beyond cost-cutting & $\begin{array}{l}\text { Gildemeister et } \\
\text { al., } 2013\end{array}$ & $\begin{array}{l}\text { A step-by-step model. Relatively } \\
\text { generic. }\end{array}$ & $\begin{array}{l}\text { No specific tools that help executives } \\
\text { initiate the strategy. }\end{array}$ \\
\hline Complexity strategy matrix & $\begin{array}{l}\text { Kaluza et al., } \\
2006\end{array}$ & A simple model that is easy to use. & $\begin{array}{l}\text { No focus on how to deliver on the } \\
\text { proposed strategy. }\end{array}$ \\
\hline $\begin{array}{l}\text { Five-step model to reduce } \\
\text { complexity }\end{array}$ & $\begin{array}{l}\text { Hansen et al., } \\
2012\end{array}$ & $\begin{array}{l}\text { A step-by-step model. Relatively } \\
\text { generic. Focuses on quantification. }\end{array}$ & Resource intensive. \\
\hline $\begin{array}{l}\text { Two-pronged assault on } \\
\text { complexity }\end{array}$ & $\begin{array}{l}\text { Wilson and } \\
\text { Perumal, } 2009\end{array}$ & Easy to understand/use. & Too simple and conceptual. \\
\hline From complexity to simplicity & $\begin{array}{l}\text { Collinson and Jay, } \\
2012\end{array}$ & $\begin{array}{l}\text { Targets complexity in various areas } \\
\text { of the organisation. }\end{array}$ & Resource intensive. \\
\hline The anti-complexity matrix & $\begin{array}{l}\text { Mahler and } \\
\text { Bahulkar, } 2009\end{array}$ & Uses $\mathrm{ABC}$ to quantify complexity. & $\begin{array}{l}\text { Methodology is not presented. Only } \\
\text { focuses on reducing product variety. }\end{array}$ \\
\hline
\end{tabular}

\subsection{Phases in complexity management}

Based on the models of Hansen et al. (2012), Hvam et al. (2020) and Gildemeister et al. (2013), the following five general steps can be described:

I. Scoping. Determine the project focus, the examined time frame, the details of the requirements and the extent of analysis required (Hansen et al., 2012; Gildemeister et al., 2013).

II. Analysing the initial portfolio. This includes $\mathrm{ABC}$ and Pareto $\mathrm{ABC}$ analysis, resulting in a general overview of the project's financial and operational impacts (Heap, 2021; Koch, 1999; Teunter et al., 2010). The objectives of the initial analysis should be based on scoping from step one (Gildemeister et al., 2013). Analyses are carried out using either a bottom-up or top-down approach, depending on the scope and level of detail expected.

III. Identifying life cycle complexity costs (LCCs). Identify, quantify and allocate complexity costs, and then perform a complexity-adjusted ABC analysis (Hansen et al., 2012). The exploratory nature of this analysis should include all relevant complexity costs that come to light during initial baseline analyses.

IV. Building future scenarios. These are based on the quantification of LCCs. An overview of the financial potential of targeting complexity with reference to Kaluza et al.'s (2006) strategy matrix should be made. Scenarios are built, and a complexity-adjusted recommendation is made to improve profitability (Hansen et al., 2012). Future scenarios vary by company, resource, capability, culture, willingness to change and industry, among other factors. The framework itself cannot determine specific activities or methods to reduce LCCs. Detailed actions to reduce complexities must be planned based on the specific complexity reduction programme and with the organisation leading the way (Hayes, 2014). Recommendations should be presented as stand-alone complexity-reducing projects and in combination, where possible.

V. Planning and implementing the complexity reduction programme. This involves the preparation of the complexity reduction programme, key performance indicators, responsibility allocation and risk assessment. Stakeholders must be managed to sustain implementation, and this requires aspects 
of project management and change management (Cooper and Kaplan, 1988; Kaplan, 2012; Gildemeister et al., 2013).

To avoid too extensive a focus, this study concentrates on the first three steps only.

\section{METHODOLOGY}

The purpose of this study was to identify the main complexity drivers in project organisations and means for addressing these. Given that the existing complexity management literature does not seem to focus on project organisations, an explorative approach was chosen. Specifically, this type of approach is generally considered appropriate when constructs for a phenomenon have yet to be clearly identified and delineated (Eisenhardt and Graebner, 2007; Yin, 2013). This was done in the form of a longitudinal case study, which allows the researcher to gain deep insights into the studied phenomena (Yin, 2013). As statistical generalisation is obviously not possible from a single case study, analytical generalisation is used (Yin, 2013).

The case company is a Danish automation company established in 1988, which provides its customers support with optimising their manufacturing processes through robotic automation. Access to the case was granted on promises of anonymity, for which reason the company is referred to as 'AuCo' instead of its real name. AuCo is a fast-growing company, which implies some challenges in maintaining efficiency. The company's objective is to achieve a contribution margin (CM) above $30 \%$ on all projects and a CM, including overheads of $20 \%$.

The case company was chosen based on the following criteria:

1. A project organisation

2. With headquarters in Denmark

3. Willing to explore complexity within the organisation

4. Open to disruptive input

5. Provides access to critical data sources, such as the detailed cost structure and labour cost

6. Has the necessary resources in terms of allocating time for interviews and workshops

Given the explorative nature of the research question and the complexity of the research area, this paper uses a mixed-method design, represented by qualitative and quantitative methodologies that allow the complexity of the research to be targeted with a qualitative strategy and a case study approach (Yin, 2013). Quantitative data sources are required to quantify the cost of complexity, whereas qualitative data enable an understanding of the origin of the complexity drivers. Jick (1979) highlights the strength of balancing quantitative and qualitative research strategies in supporting each other.

Insight into the business comes from primary data sources, specifically semi-structured interviews, observations and informal interviews in the case organisation. These data collection methods corresponded to the exploratory nature of the research and enabled the interviewer to adapt to situations and follow leads in order to gain further insights (Yin, 2013). To reduce the bias in responses, the interviews did not present the respondents with predefined categories of complexity cost factors but focused on deriving such based on the data. Information from the interviews was collected via notetaking, resulting in less pressure on the interviewee and an informal setting. Two researchers were present in all interviews to reduce the risk of overlooking something (Saunders, Lewis and Thornhill, 2009). Data was collected over a period of 11 months.

Both top management and lower-level employees were interviewed to obtain a multi-perspective view of the organisation. Table 3 summarises the key employees who contributed to the research. Approximately nine other employees also contributed to this study through informal interviews, data input and other means.

Table 3 Description of the interviewees

\begin{tabular}{lrr}
\hline Title & No. of interviews & No. of informal interviews \\
\hline CFO & 5 & $>10$ \\
CEO & 3 & $1-5$ \\
COO & 4 & $5-10$ \\
Financial Controller & 2 & $>10$ \\
Purchasing Manager & 2 & $1-5$ \\
Project Manager & 2 & $5-10$ \\
Project Manager & 2 & 0 \\
HR Manager & 1 & $1-5$ \\
PM Trainee & 3 & $>10$ \\
\hline
\end{tabular}


The secondary data were quantitative in the form of datasets in the case company's database. Such data allowed testing the assumptions on complexity drivers identified in the interviews using quantitative data registered on the projects. Specifically, the authors were granted full access to the company database, of which data was retrieved from the following areas:

- $\quad$ Sales/Customer database

- $\quad$ Project methodology (process)

- $\quad$ Production cost (incl. material, labour, etc.)

- Deviation data sets

- Financial data

\section{FINDINGS}

At AuCo, sales representatives (SRs) and project managers (PM1) complete a project's budget before transferring the project to a second project manager (PM2). This exemplifies gate 1 in their project model. At this point, the $\mathrm{CM}$ is expected to be above $30 \%$, although a lower $\mathrm{CM}$ is accepted in certain situations, such as new customers, key accounts or strategically important projects. If the project is completed without complications, the CM matches the calculated budget. However, deviations may alter the CM. Examples of negative deviations experienced by the case company include:

- Components that are more expensive than presumed

- Designs that are more difficult to construct than expected

- The need for external resources, which are often more expensive

- Processes that take more time to complete than expected

The analysis of the present study started with calculating the CMs for the projects, i.e., the difference between "revenue" and variable costs. Converting this into AuCo's project situation, the equation was formulated as:

$$
C M=\text { Sales price }+ \text { Upsell }- \text { Variable costs }+ \text { Deviations }
$$

Table 4 describes the elements of the equation.

Table 4 Elements of CM calculation

\begin{tabular}{ll}
\hline Entity & Description \\
\hline Sales price & The initial price agreed on with the customer based on the project budget calculated in the price calculator. \\
Upsell & Additional sales made during the project period. \\
Variable cost & Includes material cost, direct labour cost and external services. \\
Deviations & Positive and/or negative changes made to the project budget during the project period. \\
\hline
\end{tabular}

Figure 2 illustrates the CM per project in DKK (1 DKK equals around 0,13 Euro). Each of the vertical lines represents a project. The projects are sorted by contribution (high to low). Across all projects, the average contribution ratio equals $27 \%$, while 145 (or $53.3 \%$ ) projects had a contribution ratio below the target of $30 \%$. Twenty-two of $272(8 \%)$ projects had a negative CM with a negative average contribution ratio of $42 \%$. The two worst projects had a negative CM of over 1.5 million DKK ( 200,000 Euro). 


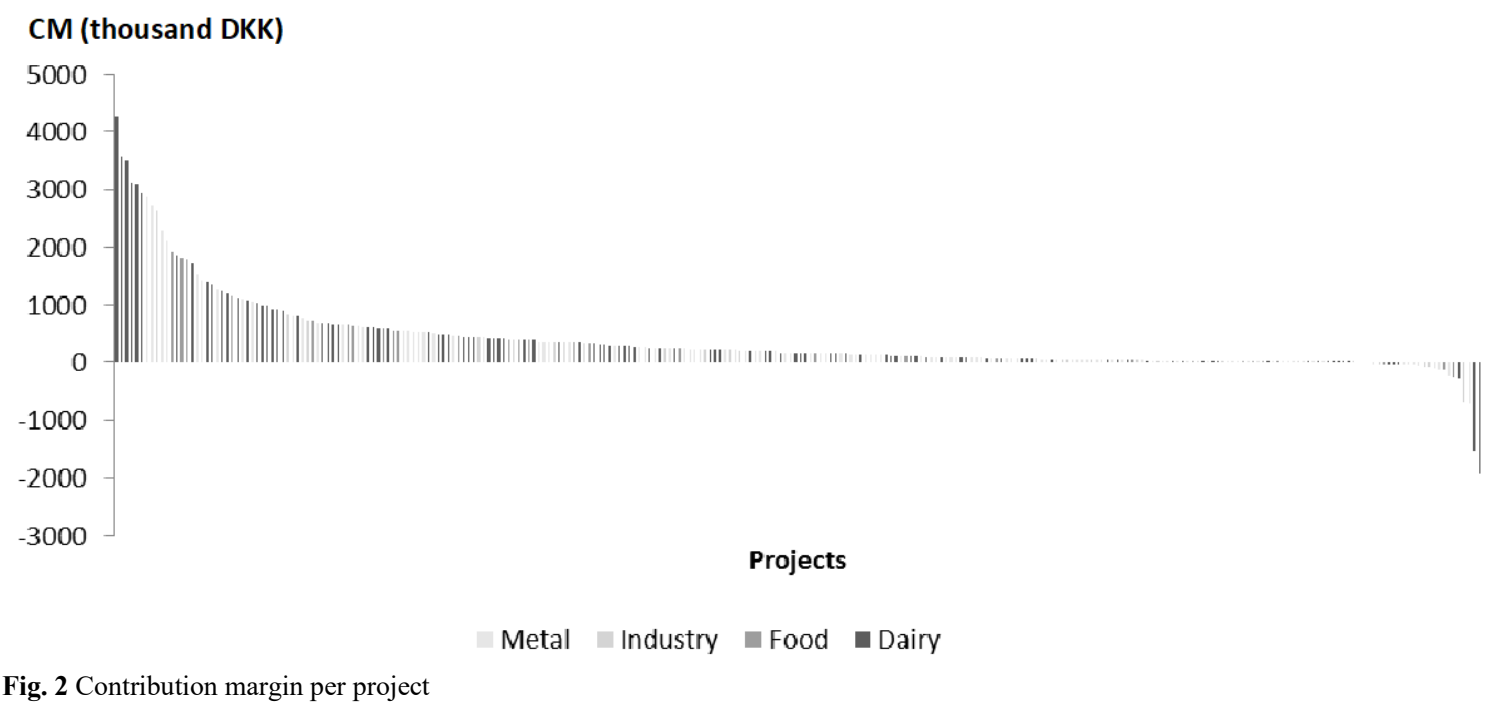

In $\mathrm{AuCo}$, the gap between the estimated and realised project costs could be categorised into four types:

1. Risk buffer

2. PM cost budget adjustment

3. Registered cost deviations

4. Nonregistered cost deviations

Point 1 and 4 represent unknown factors. Specifically, the risk buffer is defined as a fixed percentage of the estimated project costs, while the nonregistered cost deviations concern other nonregistered deviations. Point 2 and 3, on the other hand, are known entities that both are registered in IT systems. Figure 3 illustrates the gap between the estimated and realised project costs.

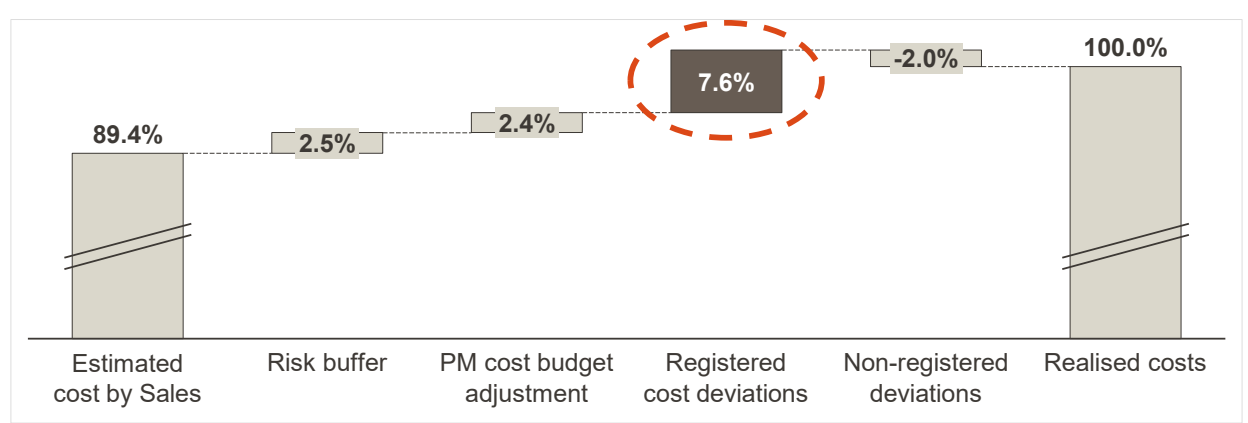

Fig. 3 Illustration of the gap between the estimated and realised project costs

Given the availability of data on registered cost deviations and the fact that these constituted more than half of the gap between estimated and realised project costs, these were used as a starting point for the analysis of their causes.

\subsection{Identified complexity drivers}

As mentioned above, $53.3 \%$ of the projects did not deliver the expected contribution ratio of $30 \%$. The causes of this were investigated through insights acquired during the interviews, followed by analyses of the costs registered on the projects. Specifically, based on the registered causes of cost deviations in the projects, the analysis identified 2,092 cost deviations across the 272 projects, which were organised into 24 categories, as shown in Table 5. 
Table 5 Categorisation of cost deviation causes

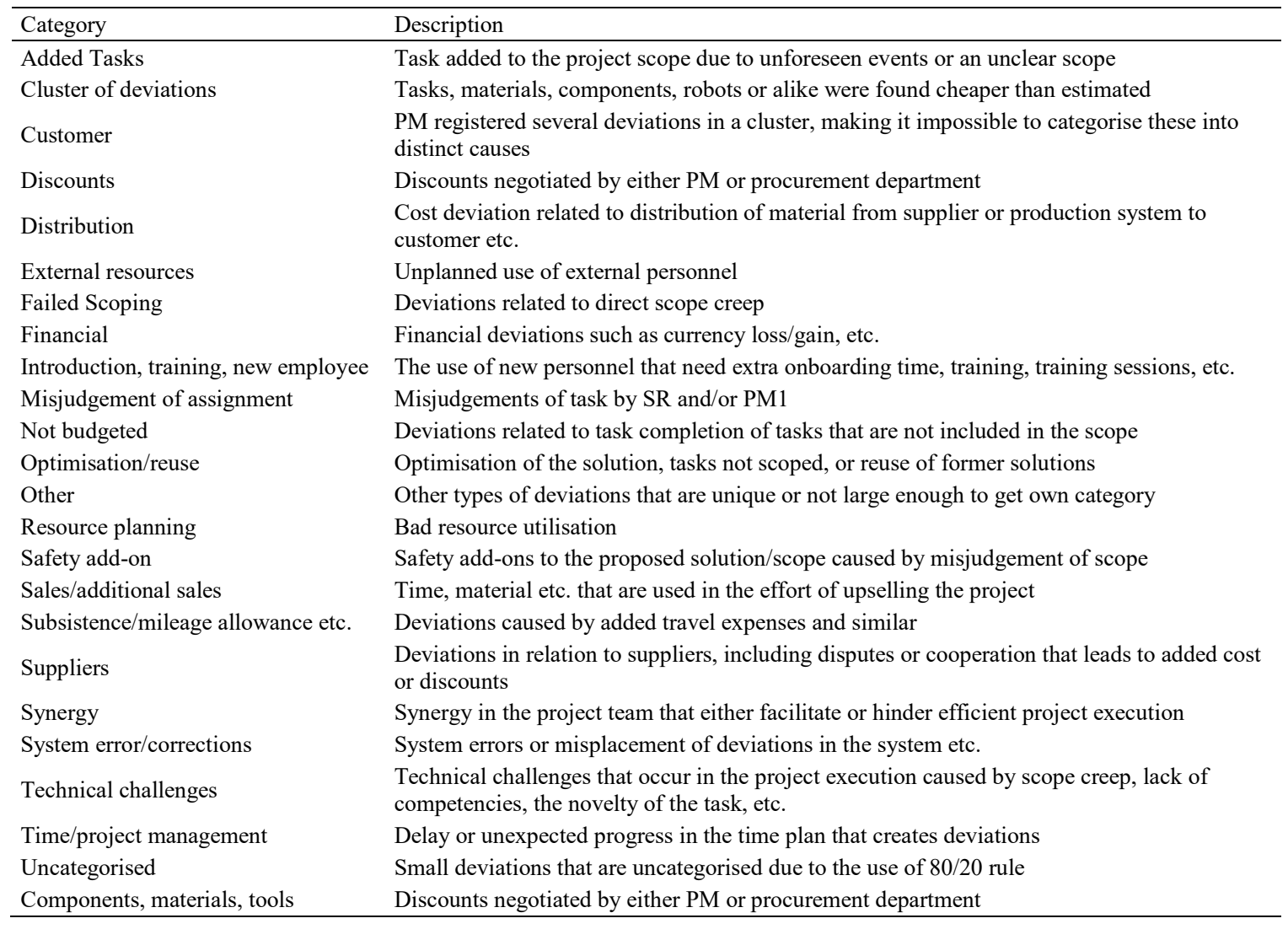

Based on the interviews, three main complexity drivers of these issued were identified. Specifically, interviewees were asked how and why these deviations occurred. These three complexity drivers are shown in Table 6.

Table 6 Main complexity cost drivers

\begin{tabular}{ll}
\hline Topics & Findings \\
\hline 1 & $\begin{array}{l}\text { Project risks: For high-risk projects, there was no correlation between the proposed risk (illustrated by the size of the risk } \\
\text { buffer) and the actual risk (illustrated by relative cost deviation). }\end{array}$ \\
2 & $\begin{array}{l}\text { Personal preferences and capabilities: It cannot be concluded whether certain SRs or PMs constantly deliver more profitable } \\
\text { projects than others do. However, as profitability varies, it is conclusive that personal preferences and capabilities influence } \\
\text { profitability. }\end{array}$ \\
& $\begin{array}{l}\text { Project management: Significant evidence that scope creep and inefficient project management are the main drivers for low } \\
\text { project profitability was found. }\end{array}$ \\
\hline
\end{tabular}

Two additional factors were identified in the interviews, but an analysis of the register data did not support their effect on complexity costs. In other words, the interviewees believed certain factors had an impact on project cost deviations, which could not be supported by the costs registered on the projects. These unsupported complexity cost drivers are shown in Table 7.

Table 7 Unsupported complexity cost drivers

\begin{tabular}{lll}
\hline Topics & Findings & Reservations \\
\hline 1 & $\begin{array}{l}\text { Site Acceptance Test (SAT) delays: Project data } \\
\text { analyses showed no direct correlation between the } \\
\text { number of days SAT is delayed and cost } \\
\text { deviations, i.e. data points and the strength of } \\
\text { direction are highly affected by randomness. }\end{array}$ & $\begin{array}{l}\text { The analyses did not cover interrelatedness and interdependencies } \\
\text { between projects. Previous studies argue that incremental costs and } \\
\text { lower personal productivity could appear as changeover time/cost and } \\
\text { will affect the implicated employees (Weinberg, 1992; Rigby et al., }\end{array}$ \\
$\begin{array}{l}\text { Project size: Analysis of project data found no } \\
\text { connection between larger projects (measured by }\end{array}$ & $\begin{array}{l}\text { The project process does not differ based on monetary scope of the } \\
\text { number of black boxes. The novelty is, therefore, eliminated from the } \\
\text { analysis. Deviations are measured in relative values, i.e., a mixture of } \\
\text { positive and negative values. }\end{array}$ \\
& &
\end{tabular}




\subsection{Addressing complexity cost drivers}

The main complexity cost drivers were analysed to identify means to address these. First, with regard to risk buffer costs, the findings showed that the monetary size of projects did not influence percentage cost deviations. The best-performing revenue group, the only one with a positive average cost deviation, is small projects with a sales price of DKK 250,000-500,000 (Euro 32,500-65,000). Evidence of a correlation between a larger monetary size and a larger sum of cost deviations was not found, arguing against monetary size as a risk component. On this basis, it was concluded that the risk category calculations are faulty, resulting in an incorrect pricing model. Thus, addressing this issue concerns defining appropriate profitability risk parameters based on factual analyses.

Second, with regard to personal preferences and capabilities, analyses found these to have a particular impact on procurement decisions. A central cause seemed to be that the use of procurement specialists was not structured, in the sense that $90 \%$ of projects were sourced without involving procurement. In other words, decisions affecting procurement were, to a large extent, made by project participants according to their preferences and capabilities, as opposed to utilising the expertise of the procurement department. Creating standardised procurement structures and governance models could reduce cost deviations related to procurement. Thus, the recommended action is to centralise procurement and create governance in order to secure a single source of procurement against suppliers.

Third, analyses found that inefficient project management (hereunder, scope creep) was the largest contributor to unprofitability. No direct relationships were found between SR scoping ability or PM project execution ability, suggesting that personal preferences and capabilities should be aligned with job specifications for the best results. Knowledge sharing internally and externally is a valuable lever to exploit for increased employee capability. AuCo's PMs often have technical backgrounds essential for the management of highly technical projects. However, not all PMs have received project management training to enhance their abilities. Thus, the recommended actions are as follows: (1) SR and PM1 validation of sales proposals to eliminate cost deviations caused by PM cost adjustment; (2) project management training of PMs to secure high-quality project execution; and (3) increase knowledge sharing between sales and PMs and amongst PMs across sectors and business units.

Based on the discussion above, this article recommends that project organisations consider the following seven guidelines in complexity management projects:

1. Assess the current state of operations to understand the true cost of serving customers

2. Segment projects and customers to differentiate the services, solutions or processes for each

3. Focus on hidden and visible complexity costs

4. Ensure that the methodology for assessing risk is fact-based and founded on elements that create risk for the organisation's future operations

5. Develop scoping processes that ensure the effective scoping of projects regardless of novelty, uncertainty and other factors

6. Focus on key cost drivers and create a culture of efficient project management by using the methodology and resources best fitted to the task

7. Utilise shared resources, such as the procurement department

\section{DISCUSSION AND CONCLUSIONS}

This paper addressed the gap in complexity management research on the identification of complexity drivers in project organisations through a case study of AuCo. The study made two main contributions. First, three main complexity drivers in the project organisation were identified: (1) project risks, (2) personal preferences and capabilities and (3) project management. The most significant of these complexity drivers was project management. Two additional complexity drivers were identified in the interviews: SAT delays and project size. However, the analysis of register data did not find any significant effects of these. Second, based on the case study, the paper developed seven guidelines to guide complexity management projects in project organisations.

The identified complexity drivers had several indicators and regressors. For instance, the study found these to be driven by "silo mentality", organisational structure, communication approach, governance systems and other elements hindering efficient operations. However, pinpointing specific drivers of particular complexity types is difficult because many of them are interrelated.

Individual capabilities and preferences, i.e. people complexity, were expected to be reflected in project profitability variations, depending on the SR in question. Varying profitability from SR to SR was found, but the variation was not systematic, and one SR could provide budget overestimations on one project and underestimations on another, adding to the suspicion that people complexity is a key complexity driver for AuCo. Similar findings were evident when analysing PM2s, indicating that either their scoping capabilities are affected by personal complexity, or the project execution phase is not being managed efficiently. Based on the data input, distinguishing the two is not possible. 
People and process complexity were identified for high-risk projects, which, on average, deviated $8 \%$ from the expected cost. The underlying reasons for this are unclear but could be related to the higher complexity of high-risk projects. No correlation in cost deviations was found between the postponement of SAT dates and monetary project size.

\subsection{Contribution to research}

In the literature study, the complexity management strategy of Hansen et al. (2012), which focuses on production companies, stood out because of its applicability and earlier results. The proposed strategy by Hansen et al. (2012) was combined with those of Wilson and Perumal (2009) and Gildemeister et al. (2013) to create a conceptual framework that served as the structural backbone for the analyses conducted in this paper. This included the following steps: 1) scoping, 2) analysis of the initial portfolio, 3) identification of LCCs, 4) development of future scenarios and 5) planning and implementation of a complexity reduction programme. The empirical studies were limited to the first three steps in agreement with the research questions. The framework functioned well because of its simple and structural approach. However, the tools and methods used in the third step needed to be modified along the way, as the exploratory nature of this study led to an enhanced focus on the causes of cost deviations.

The identification of key value drivers and complexity costs is dependent on the type of organisation. This study identified three main complexity drivers in project organisations. On this basis, a set of guidelines was proposed. Specifically, this paper proposes that the early phases of a complexity management project should move its focus from the CMs to the contribution ratio, so the analyses considered projects that add the most value per asset invested.

Prior to this paper, little research on project organisations had been conducted, none of which focused on complexity management for project organisations. Thus, this paper provides a preliminary understanding of how complexity influences project organisations.

\subsection{Contribution to practice}

The relevant cost drivers strongly depend on the particular organisation. However, similarities to the AuCo case study can be expected regarding the identified complexity cost drivers. Specifically, the main hidden complexity drivers were found in the transition from sales to project budget and in cost adjustment, which was showed to be of significant size.

Based on the findings of this study, project organisations need to pay attention to the following areas: conducting risk assessments, identification of a realistic scope, avoiding scope creep, ensuring the capability to efficiently execute projects, and using collective/shared resources/departments, such as procurement functions. Finally, the proposed seven-step procedure (Section 4.2) may support project organisations in complexity management projects.

\subsection{Limitations and future research}

The paper identified three main complexity drivers affecting project organisations. As more may exist, this paper recommends that future research on complexity in project organisations determine additional types of complexity drivers.

For project organisations, the findings from this paper showed complexity costs in project organisations camouflaged as budget deviations, unproductive time, process complexity and risk of doing business (project price determination). These are insights that should be added to frameworks dealing with complexity management in order to create more value to these frameworks for organisations.

As this research is based on a single case study, there are some obvious limitations regarding generalisability. Future research needs to conduct more studies on complexity cost drivers in project organisations. This research, however, represents an important first step towards better understanding complexity cost drivers in project organisations.

\section{REFERENCES}

Afandi, S., \& Hansen, Z.N.L. (2016). Framework for discovering supply chain complexity drivers. In Proceedings of the 23rd EurOMA Conference, 17-22 June. Trondheim, Norway.

Altenmüller, T., Stüker, T. Waschneck, B., Kuhnle, A., \& Lanza, G. (2020). Reinforcement learning for an intelligent and autonomous production control of complex job-shops under time constraints. Production Engineering, 14, 319-328.

Ashkenas, R. (2007). Simplicity-minded management. Harvard Business Review, 85(12), 101-111.

Baccarini, D. (1996). The concept of project complexity: A review. International Journal of Project Management, 14(4), 201-204

Blecker, T., \& Kersten, W. (2006). Complexity Management in Supply Chains: Concepts, Tools and Methods. Berlin: Erich Schmidt Verlag. 
Camci A., \& Kotnour T. (2006). Technology complexity in projects: Does Classical project management work? In Proceedings of PICMET 2006, Turkey, 2006, Jul., 9-13.

Collinson, S., \& Jay, M. (2012). From Complexity to Simplicity. Basingstoke, UK: Palgrave Macmillan.

Cooper, R., \& Kaplan, R.S. (1988) Measure costs right: Make the right decisions. Harvard Business Review, 66, 96-103.

ElMaraghy, H., Schuh, G., ElMaraghy, W., Piller, F., Schönsleben, P., Tseng, M., \&, Bernard, A. (2013). Product variety management, CIRP Annals, 62(2), 629-652.

Eisenhardt, K.M., Graebner, M.E. (2007). Theory building from cases: Opportunities and challenges. Academy of Management Journal, 50(1), 25-32.

Forrester, J.W. (1989). The beginning of system dynamics., Working Paper D-4165-1. Cambridge, MA: System Dynamics Group at MIT.

Gildemeister, J., Gossy, G., Klevenz, M., Messenböck, R., \& Wray, J. (2013). Six steps to achieving competitive advantage through cost excellence: Beyond cost cutting. BCG. Available at: https://www.bcg.com/publications/2013/cost-efficiency-asset-optimization-six-steps-achievingcompetitive-advantage-cost-excellence

Hansen, C. L., Mortensen, N. H., \& Hvam, L. (2012). Calculation of complexity costs: An approach for rationalizing a product program. In Proceedings of NordDesign Conference. Aalborg, Denmark: Aalborg University.

Haug, A., Hvam, L., \& Mortensen, N. H. (2013). Reducing variety in product solution spaces of engineer-toorder companies: The case of Novenco A/S. International Journal of Product Development, 18(6), 531547.

Hayes, R., \& Wheelwright, S. (1984). Restoring Our Competitive Edge: Competing through Manufacturing. New York, NY: Wiley.

Heap, J. (2021). ABC analysis/Pareto analysis. Institute of Management Services. Available at: https://www.ims-productivity.com/page.cfm/content/ABCPareto-analysis.

Hvam, L., Hansen, C. L., Forza, C., Mortensen, N. H., \& Haug, A. (2020). The reduction of product and process complexity based on the quantification of product complexity costs. International Journal of Production Research, 58(2), 350-366.

Hvam, L., Herbert-Hansen, Z. N. L., Haug, A., Kudsk, A., \& Mortensen, N. H. (2017). A framework for determining product modularity levels. Advances in Mechanical Engineering, 9(10), 1-14.

Jick, T.D. (1979). Mixing qualitative and quantitative methods: Triangulation in action. Administrative Science Quarterly, 24(4), 602-611.

Kaplan, G. (2012). Inequality and the life cycle. Quantitative Economics, 3(3), 471-525.

Kaluza, B., H. Bliem, H. Winkler. 2006. Strategies and metrics for complexity management in supply chains. In T. Blecker, \& W. Kersten (Eds.), Complexity Management in Supply Chains: Concepts, Tools and Methods. Berlin, Germany: Erich Schmidt Verlag, pp. 3-20.

Koch, R. (1999). The 80/20 Principle: The Secret to Achieving More with Less. New York, NY: Crown Business.

Kohr, D., Budde, L., \& Friedli, T. (2017).Identifying Complexity Drivers in Discrete Manufacturing and Process Industry. Procedia CIRP, 63, 52-57.

Kuhnle, A., \& Lanza, G. (2019). Investigation of closed-loop supply chains with product refurbishment as integrated location-inventory problem. Production Engineering, 13, 293-303.

Mahler, D., \& Bahulkar, A. (2009). Smart complexity. Strategy and Leadership, 37(5), 5-11.

Saunders, M., Lewis, P., \& Thornhill, A. (2009). Research Methods for Business Students. New York, NY: Pearson.

Rauch, E., Dallasega, P., \& Matt, D. T. (2018). Complexity reduction in engineer-to-order industry through real-time capable production planning and control. Production Engineering, 12, 341-352.

Scheiter, S., Scheel, O., \& Klink, G. (2007). How Much Does Complexity Really Cost? Düsseldorf: A.T. Kearney.

Schuh, G., Arnoscht, J., Bohl, A. et al. (2011). Assessment of the scale-scope dilemma in production systems: an integrative approach. Production Engineering, 5, 341-350.

Schuh, G., Monostori, L. Csáji, B. Cs. \& Döring, S. (2008). Complexity-based modeling of reconfigurable collaborations in production industry. CIRP Annals - Manufacturing Technology. 57, 445-450.

Sheffield, J., Sankaran, S., \& Haslett, T. (2012) Systems thinking: Taming complexity in project management. On the Horizon, 20(2), 126-136.

Shenhar, A.J., \& Dvir, D. (2004). How projects differ, and what to do about it. In P.W.G. Morris, \& J.K. Pinto (Eds.), The Wiley Guide to Project, Program and Portfolio Management. Hoboken: Wiley, pp 1265-1286. 
Sowade, S., Chan, L. \& Scholz-Reiter, B. (2013). Modelling of requirements and technical enablers of the infrastructure of autonomous logistic processes: a prerequisite for their configuration. Production Engineering, 7, 101-110.

Svejvig, P., Ehlers, M., Adland, K.T., et al. (2016). Project Half Double, Preliminary Results for Phase 1, June 2016. Aarhus, Denmark: Aarhus University.

Teunter, R. H., Babai, M. Z., \& Syntetos, A. A. (2010). ABC Classification: Service levels and inventory costs. Production and Operations Management, 19(3), 343-352.

Wildemann, H. (2005). Management leistungswirtschaftlicher Risiken in der Produktion. Zeitschrift fuer Wirtschaftlichen Fabrikbetrieb, 100(4), 187-191.

Wilson, S. A., \& Perumal, A. (2010). Waging War on Complexity Costs. New York, NY: McGraw Hill.

Yin, R.K. (2013). Case Study Research: Design and Methods. Thousand Oaks: Sage. 